\title{
JAPANESE METROPOLITAN STRUCTURE DEFINED THROUGH CORRELATED DEMOGRAPHICS AND LOCAL SERVICE SECTOR EMPLOYMENT PROVISION
}

\author{
A. STAN \& A. DEGUCHI \\ Department of Socio-cultural Environmental Studies, Graduate School of Frontier Sciences, \\ The University of Tokyo, Japan.
}

\begin{abstract}
The relatively recent shift from an industrial to a post-industrial society has produced significant changes in the structure of metropolitan areas at a global level. Following the communication revolution and implicitly a spatial dispersion of economic centres, the metropolis becomes a polycentric mass with increased flexibility and less clear boundaries. While the process of global urbanisation continues, most urban growth happens in the urban periphery, which gains a key role in regional development, often even competing with central cities. Highly developed metropolitan areas beyond the core city are now essential for urban competitiveness. Polycentric development and the post-industrialisation of metropolitan peripheries happens in Japan in the particular context of population ageing and decline which, through decreasing densities, impacts the service provision, infrastructure and the urban fabric as a whole. Through statistical analysis, this paper investigates the correlation between local tertiary service employment provision and population evolution between 1995 and 2015, in the three largest major metropolitan areas in Japan, Tokyo, Keihanshin and Chukyo. Furthermore, a combined quantitative and qualitative approach was used in order to identify, within the three metropolitan areas, regions where service sector employment is high and correlated with population growth. The study is intended to serve as a possible basis for further metropolitan restructuring that can tackle population and implicitly urban shrinkage.
\end{abstract}

Keywords: Chukyo, Keihanshin, metropolitan structure, population decline, post-industrial, service sector, Tokyo.

\section{INTRODUCTION}

Post-industrialisation, as a fundamental shift in the economy, is defined by the loss of primacy of manufacturing in favour of services, in both share of GDP and employment. The concept was coined in 1969 by French sociologist Alain Touraine but was made known by Daniel Bell in his book "The Coming of Post-industrial Society" in which he attempts to define the transition from manufacturing to services that began in developed economies after WWII. Bell, as well as Clark, thinks this transformation to be rooted in the reorientation of consumerist focus from goods to services of increasing complexity and thus in a simple change in demand typology [1].

Since then, this theory has drawn significant criticism, as research has proven repeatedly that there is no evidence of consumerist decline but, on the contrary, the demand for goods continues to grow. These criticisms don't deny the existence of the post-industrial phenomenon but limit themselves to challenging the supposed consumerist decline causality. Some research argues that a significant share of tertiary sector growth happens due to an increase in services related to manufacturing, like distribution, insurance, banking and finance [2]. Other research presents increased labour productivity in manufacturing (due to technological developments and mechanisation) as a more accurate explanation for labour market restructuring and service sector employment growth. Another theory, that of the "Stagnant services" [3], attributes the growth of employment in services to low sector productivity but ever increasing 
prices. Regardless of the cause, all theorists are in agreement with service sector employment as a main indicator of post-industrialisation.

Growth of the service sector has implications that surpass the socio-economic and influence spatial structures all over the globe, especially in countries with developed economies. It plays a part in shaping urban fabrics and, more importantly, generates new city structures. Urban areas are no longer dependent on mass production or assembly lines and are no longer labour intensive [4]. Former industrial, rigid urban structures based on commuting are now made obsolete by the relocation of employment centres liberated by the information age from being bound to city cores. Therefore, a new type of urbanisation becomes possible with the dispersion of employment due to overcrowded and expensive city centres [5].

Service sector predominance and its urban manifestations have been thoroughly researched in developed countries, but mostly in the context of both economic and demographic growth [5]. Following excessive economic and demographic growth for most of the 20th century, Japan entered the post-industrial age first with a stagnant population in the 1990s. Soon after, the country started experiencing population ageing and decline that has become more and more accentuated and is expected to continue well into the 21 st century [6]. The level of shrinkage currently present in Japan goes beyond the very common "rural decline - urban growth" or decline of former industrial cities.

The overall declining population in Japan, though more present in rural areas, is currently affecting metropolitan areas as well, with implications that go further than economic issues and labour shortage. The decrease in density affects health, social and education service provision renders transportation and amenities infrastructure cost ineffective, alters housing demand and accentuates regional disparities [6]. As current metropolitan structures in Japan are a consequence of accelerated industrial growth, contemporary policy and planning must tackle current shrinkage through a spatial restructuring process that addresses population decline.

\section{PURPOSE}

The overall purpose of this study is to provide a basis for the necessary metropolitan spatial restructuring process that is essential in tackling the issue of population ageing and decline. As densities decrease and both physical and service infrastructure become more expensive, urban strategic planning will play a key role in redesigning the spatial configuration of metropolitan areas. Identifying regions that still exhibit population growth correlated with high service sector employment can be a starting point for future urban public policy.

\section{OBJECTIVES}

1. To establish a correlation between a higher ratio of local tertiary sector employment and both population increase and a lower median age.

2. To spatially define, based on the previously established employment thresholds and population evolution, development regions within the three studied metropolitan areas.

\section{DATA AND METHODOLOGY}

\subsection{Study area}

This study focuses on the largest three Major Metropolitan Areas (MMA) in Japan. According to The Statistics Bureau of Japan, a metropolitan area consists of one or more core cities and the surrounding municipalities that have at least $1.5 \%$ of their workforce (over 15 years old) 
commuting to one of the core cities. Metropolitan areas also include municipalities that don't meet this criterion but are surrounded by municipalities that do. The Major Metropolitan Area statute is given when the core city or cities have a designated city statute. A designated city is a city with a population larger than 500000 that was granted this statute through governmental ordinance.

The choice of study area represented in Fig. 1, while easily justified through size, is rather rooted in the fact that the three Major Metropolitan Areas together form the Tōkaidō industrial corridor and are part of the Tōkaidō Megalopolis. While it could be argued that the Tōkaidō Megalopolis includes Hiroshima and extends all the way south to Kitakyushu and Fukuoka, urban development scale differs greatly between the corridor and the remaining area, hence the paper's focus on the urban areas that were historically part of the Tōkaidō region.

Overall, a total of 434 municipalities were included, distributed as follows:

1. Tokyo: 218 municipalities out of which a total of 28 including the 23 Tokyo Special Wards, Yokohama, Kawasaki, Sagamihara, Chiba City and Saitama City are designated metropolitan cores.

2. Keihanshin: 132 municipalities out of which a total of 4 including Osaka, Kyoto, Kobe and Sakai are designated metropolitan cores.

3. Chukyo: 84 municipalities out of which only Nagoya is a designated metropolitan core.

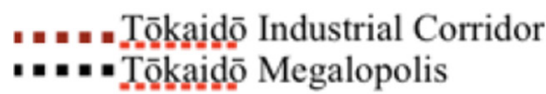

Major Cities:

1. Tokyo

2. Yokohama

3. Nagoya

4. Kyoto

5. Osaka

6. Kobe

7. Hiroshima

8. Kitakyushu

9. Fukuoka

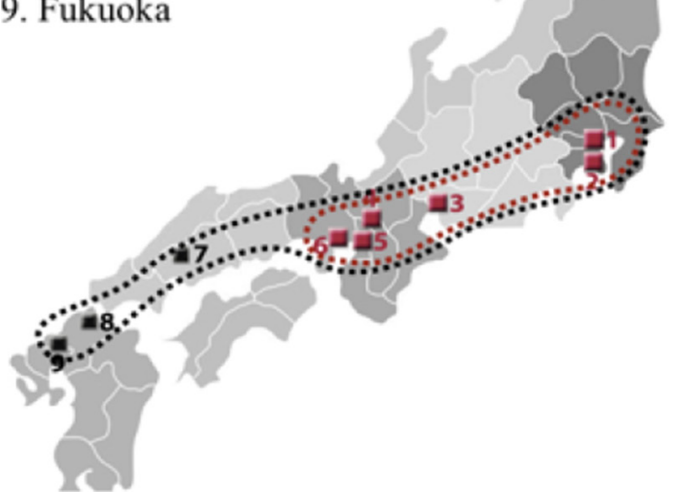

Figure 1: Tokaido Industrial Corridor and Tokaido Megalopolis. 


\subsection{Data}

For the three Major Metropolitan Areas analysed, data were collected at a municipality level using as unique source The Statistics Bureau of Japan. Local sectoral employment and demographic data were retrieved from the 2009, 2004, 1999 and 1994 Economic Census, respectively, 2015, 2010, 2005, 2000 and 1995 Census.

\subsection{Paper structure and methodology}

1. A synthetic literature review was used to introduce the topic of post-industrialisation defined as the preponderance of service sector employment and its urban implications.

2. The demographic impact of service sector growth was evaluated through quantitative research, specifically statistical analysis. Correlation and linear regression analysis were conducted to assess the existence and significance of correlations between local tertiary sector employment ratios and both population evolution and population age.

3. The spatial distribution analysis uses a combined qualitative and quantitative approach to define development regions within the studied metropolitan areas. Within the total number of municipalities, the ones with service sector employment ratios higher than the core's low and average were identified and grouped into the regions of development.

\section{DEMOGRAPHIC CHANGE AND THE SERVICE SECTOR}

The phenomenon of shrinking or population decline is not new and has manifested around the world, especially correlated with economic sectoral restructuring. Industrialisation, through an increase in employment in the secondary sector has inevitably caused shrinkage in rural areas, while the shift to post-industrialisation had a similar effect on industrial cities. This type of decline is localised and is mostly caused by out - migration.

What is new in the Japanese context is the ageing component, a phenomenon that characterises countries with advanced economies. Ageing societies are defined by a death rate that surpasses birth rates and in or out - migration, and is usually assessed at a regional or national level [6].

\subsection{Declining population}

In order to assess the correlation between service sector development and recent population evolution in the studied Major Metropolitan Areas, Pearson correlation analyses were performed between local service sector employment ratios and succeeding time frame population evolution as follows:

- $\quad$ service sector employment ratio 1994 and population evolution between 1995 and 2000

- service sector employment ratio 1999 and population evolution between 2000 and 2005

- $\quad$ service sector employment ratio 2004 and population evolution between 2005 and 2010

- $\quad$ service sector employment ratio 2009 and population evolution between 2010 and 2015

The results of the correlation analysis are displayed in Table 1 and imply that the correlation has been highly significant (at the 99\%) level in the case of both Tokyo and Keihanshin MMAs, as well as for the three MMAs analysed together. However, Chukyo MMA shows no correlation for none of the four studied time frames. Where the correlation is significant, the 
Table 1: Population evolution Pearson correlation results.

\begin{tabular}{lllllllll}
\hline & 1994 & & 1999 & & 2004 & \multicolumn{2}{l}{2009} & \\
\hline & $\mathrm{p}$ & $\mathrm{R}$ & $\mathrm{p}$ & $\mathrm{R}$ & $\mathrm{p}$ & $\mathrm{R}$ & $\mathrm{p}$ & $\mathrm{R}$ \\
\hline Tokyo & 0.0022 & 0.2066 & 0.0000 & 0.3368 & 0.0000 & 0.3100 & 0.0000 & 0.4017 \\
Keihanshin & 0.0019 & 0.2673 & 0.0001 & 0.3247 & 0.0001 & 0.3397 & 0.0010 & 0.2828 \\
Chukyo & 0.9406 & 0.0083 & 0.8876 & 0.0157 & 0.9415 & 0.0081 & 0.4467 & 0.0841 \\
Cumulated & 0.0015 & 0.1517 & 0.0000 & 0.2474 & 0.0000 & 0.2132 & 0.0000 & 0.2297 \\
\hline
\end{tabular}

correlation coefficients (R) show weak to moderate strength, which in this case signifies that, as expected, there are other factors that influence population growth or decline.

The coefficients in Table 1 show that where the correlation exists it is of growing strength throughout the studied time frames, which implies that future service sector employment ratios could have a higher impact on demographics. The only exception is Keihanshin MMA which shows decrease in strength on the most recent time interval, which could be related to the fact that it is the only MMA with negative population evolution (decline).

In order to quantify the relationship between third sector employment and population evolution, a linear regression analysis was performed on the cumulated data set as well as Tokyo and Keihanshin MMAs using the following variables:

$\mathrm{Er}=\mathrm{Sj} * 100 / \mathrm{Tj}-$ independent variable

- $\mathrm{Er}=$ service sector employment ratio

- $\mathrm{Sj}=$ number of local service sector jobs

- $\mathrm{Tj}=$ total number of local jobs

$\operatorname{Pr}=(\operatorname{Py} 1-\mathrm{Py} 2)^{*} 100 / \mathrm{Py} 2-$ dependent variable

- $\operatorname{Pr}=$ population evolution ratio

- $\quad$ Py 1 = population according to the year y1 census

- $\quad$ Py2 = population according to the year y2 census

- $\mathrm{y} 2=\mathrm{y} 1-5$

The linear regression analysis performed on the cumulated data set corresponding to 434 municipalities returned values that show significance at the $99 \%$ level for the Pearson correlation, the analysis and prediction. However, the B value implies that a $10 \%$ increase in tertiary sector local employment would be correlated with only $0.9 \%$ increase in the population.

Considering that the three major metropolitan areas studied are three different spatial entities that could be influenced by independent factors, the linear regression analysis was repeated separately for Tokyo and Keihanshin MMAs. The results are shown in Table 2.

Tokyo MMA (218 municipalities) shows the strongest Pearson correlation, ANOVA significance and prediction significance at the $99 \%$ level in all the four studied timeframes. For the most recent time frame, 2010-2015, the R sq. value implies that local tertiary employment has a $16 \%$ significance for population evolution while the B value establishes the correlation between $10 \%$ tertiary employment increase and $1.8 \%$ population growth in a time frame of 5 years. 
Table 2: Regression analysis results.

\begin{tabular}{llllllll}
\hline & $\mathrm{p}$ & $\mathrm{R}$ & $\mathrm{Rsq}$ & \multicolumn{2}{l}{ ANOVA sig $\mathrm{B}$} & $\mathrm{t}$ & $\mathrm{t}$. sig \\
\hline Total & 0.0000 & 0.2300 & 0.0500 & 0.0000 & 0.0900 & 4.9060 & 0.0000 \\
Tokyo & 0.0000 & 0.4020 & 0.1600 & 0.0000 & 0.1800 & 6.4500 & 0.0000 \\
Keihanshin & 0.0010 & 0.2050 & 0.0500 & 0.1084 & 0.0800 & 2.3870 & 0.0184 \\
\hline
\end{tabular}

Keihanshin MMA (132 municipalities) shows a strong Pearson correlation, ANOVA significance and prediction significance at the $99 \%$ level, but not as strong as Tokyo MMA. The $\mathrm{R}$ square value implies that local tertiary employment has only a $5 \%$ significance for population evolution while the B value establishes the correlation between $10 \%$ tertiary employment increase and $0.8 \%$ population increase in a time frame of 5 years.

Chukyo MMA (84 municipalities) shows no significant Pearson correlation between service sector employment ratio and population evolution in none of the studied time frames, therefore no regression analysis was needed.

If we compare the correlation graphs displayed in Fig. 2 we can see that the ascending trend is most clearly visible for Tokyo MMA while Chukyo MMA shows a scattered distribution with no visible correlation. It is also noticeable that both Tokyo and Keihanshin MMAs show a higher variation when it comes to population evolution, exhibiting growth as high as approx. $20 \%$ and decline as low as approx. 15\%. Chukyo MMA's municipalities are almost exclusively situated between the $-10 \%$ and $10 \%$ thresholds, which implies a more unified character of MMA.

Overall, there is a strong correlation between service sector development and recent population evolution in all three metropolitan areas, which supports the idea that service sector
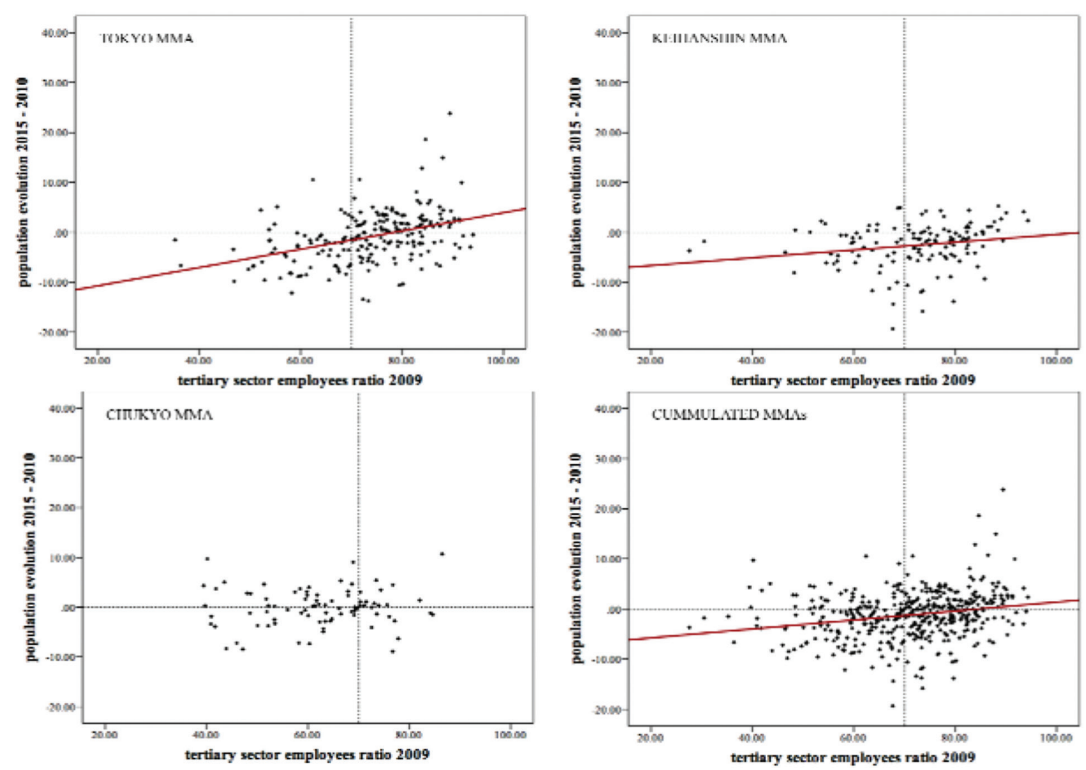

Figure 2: Correlation graphs between population evolution 2015-2010 and tertiary sector employment ratio 2009. 
Table 3: Median age Pearson correlation results.

\begin{tabular}{llll}
\hline & $\mathbf{1 9 9 4}$ & $\mathbf{1 9 9 9}$ & $\mathbf{2 0 0 4}$ \\
\hline Tokyo & 0.4417 & 0.3601 & 0.2385 \\
Keihanshin & 0.0311 & 0.0209 & 0.4430 \\
Chukyo & 0.0756 & 0.2028 & 0.6779 \\
Cumulated & 0.4518 & 0.0280 & 0.0000 \\
\hline
\end{tabular}

growth oriented policy and planning cannot only strengthen the polycentric character but also help restructure metropolitan areas from a demographic perspective.

\subsection{Population ageing}

Starting from the hypothesis that high population growth implies a younger population the study was continued with an investigation of possible negative correlations between tertiary sector local employment and median age. Since the 2015 median age data was not yet available at the time the study was conducted, this research used data as follows:

- $\quad$ service sector employment ratio 1994 and median age evolution between 1995 and 2000

- service sector employment ratio 1999 and median age evolution between 2000 and 2005

- service sector employment ratio 2004 and median age evolution between 2005 and 2010

The correlation analysis performed on the cumulated data set returned p values which show that while the correlation does not exist for the 1994 employment data, it does exist at the 0.05 level for 1999 and at 0.01 level for 2004. While the correlation seems to become stronger in time for the cumulated data set, the analysis for each metropolitan returned few $\mathrm{p}$ values lower than 0.05 , not enough to conclude that there is a strong correlation.

The individual analysis concluded that, in fact, a correlation is present only in the case of Tokyo MMA and Keihanshin MMA, which represent approx. $80 \%$ of the studied area, though in the case of Keihanshin the significance is only at 0.05 level. As in the case of population evolution, in the case of Chukyo MMA there is no correlation between service sector employment and median age decrease. Overall, the correlation coefficients show much less strength than in the case of population evolution.

Though initially expected that correlations between local tertiary service employment and population evolution, respectively, median age would be similar, the results show that the development of the service sector has a lesser impact on population age. One possible factor could be gentrification: growing areas, as they continue to be developed, become cost prohibitive for a younger segment of the population.

\section{SPATIAL STRUCTURE}

As opposed to European cities that gravitated around a central square and were historically contained by city walls, Japanese cities have a tradition of unhindered sprawl and alternating densities. Intensive urbanisation happened in Japan only after the Meiji restoration when development took place along numerous, scattered, urban or rural local centres [7]. Thus, through its initial polycentric profile to which a railway structure that ensures connection and mobility was added, the Japanese urban setting should adapt easily to a new, post-industrial structure. 
The post-industrial "Information Age" with its labour flexibility has had an impact on Japanese metropolitan areas through employment centres mobility towards the suburbs in pursuit of lower costs. In addition to the post-industrial phenomenon common to all developed countries, disaster prevention exerts additional pressure on Japan's service employment to relocate outside the core to lower densities and diminish disaster risks [8].

This study attempts to identify within the three studied MMAs possible development regions based on combined population growth and local service sector employment ratios. For this purpose, the following thresholds were established for both indicators:

- population growth higher than MMA average

- population growth lower than MMA average

- local service sector employment ratio higher than core city average

- local service sector employment ratio lower than core city average but higher than core city minimum

- local service sector employment ratio lower than core city minimum

With a population of $37,309,327$ according to the 2015 census, Tokyo MMA is the largest metropolitan area analysed in this study. Despite Japan's population decline, the MMA shows an average growth of $1.43 \%$ in the 2010-2015 interval, decreasing from the $3.55 \%$ exhibited between 2015 and 2010. Service sector employment ratio average in 2009 was 81.32\%, with 111 out of 218 municipalities over the $75 \%$ core minimum and 36 that surpass the core average of $84 \%$, while only 96 municipalities showing population growth. Through data mapping we can conclude that Tokyo MMA development starts from a basic circular pattern supported by the 23 Tokyo Special Wards, Kawasaki and Yokohama continuity. The growing area has a dual circular - radial configuration due to the combined influence of a strong polarising city core and a radial railway network. Further research should extend to an analysis of the current railway network and mobility trends to more clearly define the radial trend of the MMA's structure.

According to the 2015 census, Keihanshin MMA has a population of 19,253,418 and population evolution of $-0.46 \%$, making it the only one of the three MMAs in this study to exhibit decline. The average service sector employment ratio $78.17 \%$, lower than Tokyo MMA but higher than Chukyo MMA. Out of 132 municipalities, 65 have service employment ratios higher than the core low of $75 \%$ and only 29 surpass the core average of $82 \%$,

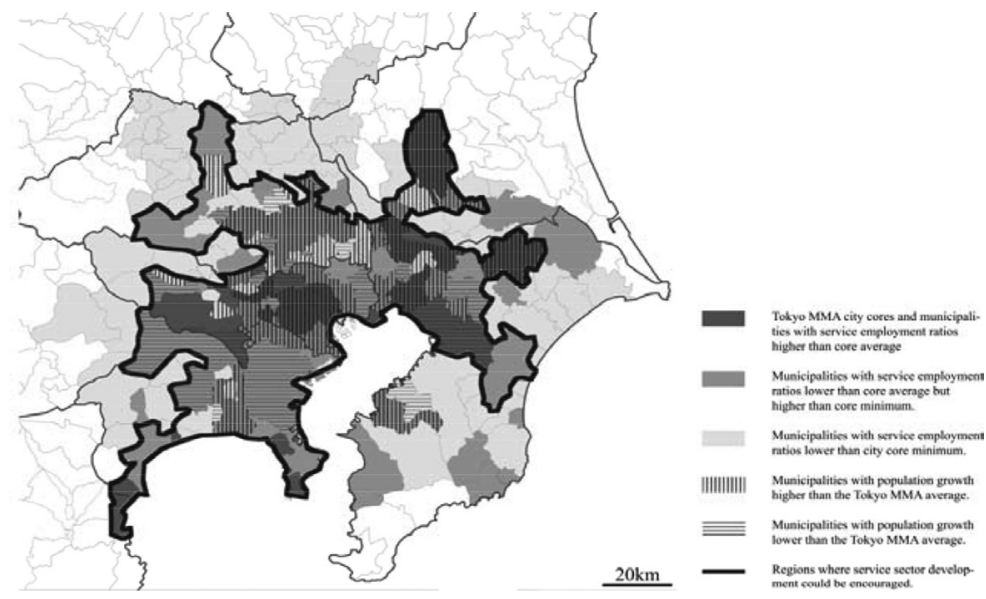

Figure 3: Tokyo MMA service employment ratio and population evolution. 


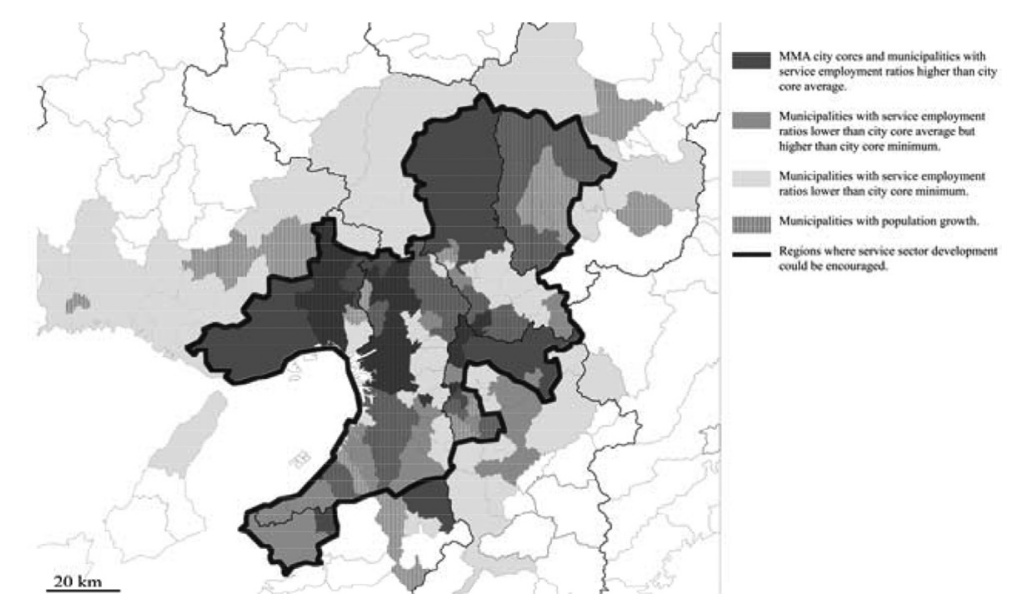

Figure 4: Keihanshin service employment ratio and population evolution.

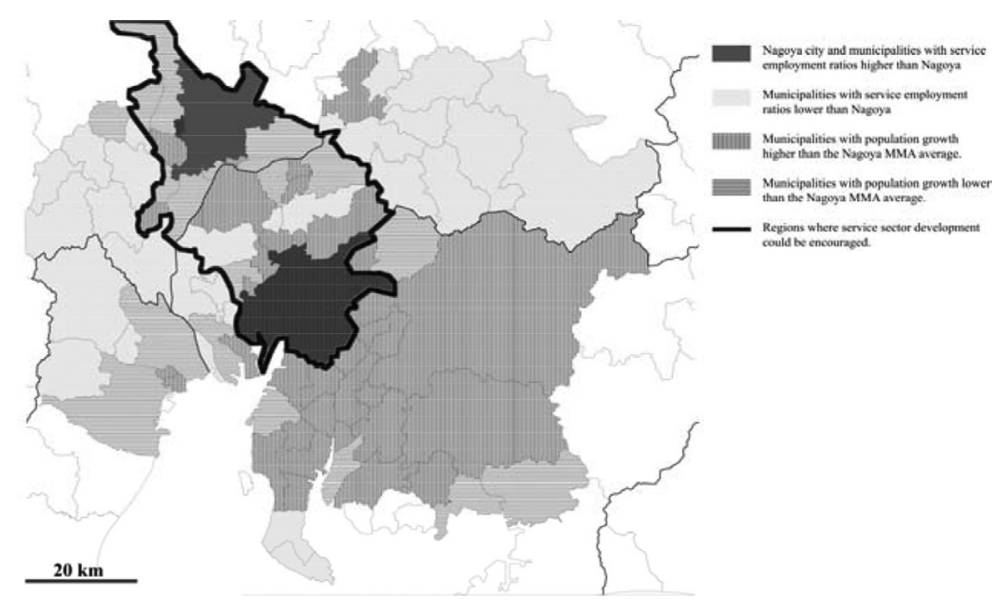

Figure 5: Chukyo MMA service employment ratio and population evolution

while only 40 have a growing population. This metropolitan area follows a triangular development pattern generated by its 3 main core cities: Osaka - Sakai, Kobe and Kyoto and supported by the position of its secondary cores, Nara and Wakayama. Both service sector employment and population growth follow and support the triangular structure, growing in the triangle's proximity. Further research should focus on supporting the particular triangular structure simultaneously with identifying potential new service employment centres.

The smallest in size and with an average tertiary employment ratio of $64 \%$, Chukyo MMA has a very strong industrial character, only 4 out of its 84 municipalities surpassing the Nagoya's $82 \%$ service sector employment. Despite this, according to the 2015 census, Chukyo's population grew by $2.16 \%$ to reach $4,882,110.43$ municipalities have population growth out of which 23 are over the MMA average. Overall, the metropolitan area is homogenous, the whole south eastern part having very low tertiary service employment but despite this, showing population growth over the MMA average. Very small areas meeting the predefined service sector employment criteria can be observed in the north-eastern part mostly in relation to the secondary pole, Gifu City. Having only one core city, the shape is circular, but no 
clear structure can be determined and cannot be compared to the other Japanese MMAs that this study focuses on.

\section{CONCLUSIONS}

This study attempts to establish a correlation between local service sector employment provision and population evolution and age in Japanese Metropolitan Areas; there is a strong correlation between population evolution and local service sector employment ratios. The hypothesis that a similar relationship exists between local service sector employment ratios and population age and has not been proven. Third sector employment ratios stronger correlated with population evolution than with population age imply that service sector development does not affect natural population growth but rather increases the attractiveness generating inward migration.

Both population growth and tertiary sector employment ratio were used to determine growth regions within the three studied MMAs;

Tokyo MMA has the highest population growth and service sector employment as well as strongest correlations between the two.

Keihanshin MMA presents a population that started to decline in the interval 2010-2015 and service sector employment lower than Tokyo MMA but higher than Chukyo MMA. The three indicators, population, age and employment are also correlated, though with weaker coefficients. Having three significant cores, it shows a triangular spatial structure that is only enhanced service sector employment and population evolution maps.

Chukyo MMA, the smallest of the three metropolitan areas, shows no correlation between service sector employment and either population evolution or age. With the lowest service employment of the three MMAs, Chukyo still exhibits a strong industrial character mostly due to the major industrial pole - Toyota City.

\section{RECOMMENDATIONS}

Further development of Tokyo and Keihanshin MMAs should follow the existing spatial structure and should be discouraged in the more remote declining areas that still show a strong industrial character.

Since any growth in service sector employment has no impact on population evolution in Chukyo MMA, it should be determined how a post-industrial dynamic can exist within an industrial environment.

\section{REFERENCES}

[1] Bell, D., The Coming of Post-industrial Society, Basic Books: New York, 1973.

[2] Gershuny, J.I., Post-industrial society: the myth of the service economy. Futures, 9(2), pp. 103-114, 1977. https://doi.org/10.1016/0016-3287(77)90003-9

[3] Baumol, W.J., Macroeconomics of unbalanced growth: the anatomy of urban crisis. American Economic Review, 57, pp. 415-426, 1967.

[4] Phelps, N.A., Parsons, N., Ballas, D. and Dowling, A., Post-Suburban Europe: Planning and Politics at the Margins of Europe's Capital Cities, Palgrave McMillan: New York, 2006. https://doi.org/10.1057/9780230625389

[5] Garreau, J., Edge City: Life on the New Frontier, Anchor Books: New York, 1991.

[6] Matanle, P. and Rausch, A.S., Japan's Shrinking Regions in the 21st Century, Cambria Press: New York, 2011.

[7] Hidenobu, J., Tokyo - A Spatial Anthropology, University of California Press, 1995.

[8] Satō Hideto, 東京大都市圈郊外の変化とオフィス立地.オフィス移転 からみた 業務核都市の姿, Tokyo, 2016. 